\title{
A Review on COVID-19 Mediated Impacts and Risk Mitigation Strategies for Dental Health Professionals
}

\author{
Shikha Sharma ${ }^{1} \quad$ Abhishek Parolia $^{2}$ Shalini Kanagasingam ${ }^{3}$
}

\begin{abstract}
Address for correspondence Abhishek Parolia, BDS, MDS, MFDSRCPS (Glasgow), MFDSRCS (Edinburgh), PhD, Division of Clinical Dentistry, School of Dentistry, International Medical University (IMU), 126, Jalan Jalil Perkasa 19, Bukit Jalil 57000, Kuala Lumpur, Malaysia (e-mail: abhishek_parolia@imu.edu.my, paroliaabhi@gmail.com).
\end{abstract}

Eur J Dent:2020;14(suppl S1):S159-S164

\begin{abstract}
In the light of coronavirus disease 2019 (COVID-19), dentistry is facing unprecedented challenges. The closure of clinics has impacted dental health professionals (DHPs) not only financially but also psychologically. In this review, these consequences are discussed in detail to highlight the challenges that DHPs are facing thus far, in both developing and developed nations. Compromised mental health among DHPs is an

Keywords

- education

- dentistry

- pandemics

- standards important area that requires attention during this difficult period. Although, in previous pandemics, dentists have not worked on the frontline, the article discusses how their wide range of skillsets can be leveraged if another wave of COVID-19 pandemic appears. Finally, guidelines to reopen clinics and patient management have been discussed in detail that could serve as a quick reference guide for DHPs.
\end{abstract}

\section{Introduction}

The escalating impacts of novel coronavirus disease 2019 (COVID-19) pandemic on dentistry have critically affected numerous dental health professionals (DHPs) ${ }^{1}$ that include dentists, dental hygienists, dental assistants, and dental technicians worldwide. This has given rise to several questions on what will be the definition of "Normal" after the pandemic ends. The spread of novel COVID-19 infection started in China where it was recognized as a Category B infectious disease, because of which DHPs were advised to follow infection control guidelines defined as per Category A infectious disease. ${ }^{2}$ Next, in Germany, ${ }^{3}$ and in many similar incidents world over, asymptomatic hosts were identified who had already transmitted the infection to healthy contacts. The World Health Organization (WHO) reported it as an international public health emergency on January 30, 2020 due to rapidly multiplying, chain of transmissions worldwide, and ultimately declared COVID-19 as a global pandemic on March 3, 2020. ${ }^{4}$ In a recent report, it has been reported dentists as DHPs to be at greatest risk when it comes to COVID-19 infection, considering their high-risk

DOI https://doi.org/

$10.1055 / \mathrm{s}-0040-1718240$

ISSN 1305-7456. work environment. ${ }^{5}$ As a result, the dental authorities of many affected countries implemented a rapid blanket ban on all elective dental procedures to be performed by DHPs, with exception of limited emergency procedures only. 2,5

This review is an attempt to highlight the effect of this pandemic on DHPs, and discuss the immediate and long-term consequences on the dental profession.

\section{Psychological Impact}

The discontinuation of routine dental practice because of the widespread COVID-19 infections has caused serious psychological setbacks, with numerous DHPs developing anxiety and depression. There are several reasons why the dental fraternity could be more prone to stress in times of pandemic, than normal times. DHPs are usually habituated to long working hours, dealing with multiple patients, taking difficult and complex decisions, formulating treatment plans, performing exhaustive treatment procedures, and engaging in multidisciplinary discussions. They are perfectionists and desire near ideal results to best satisfy

\section{(C) 2020. European Journal of Dentistry.}

This is an open access article published by Thieme under the terms of the Creative Commons Attribution-NonDerivative-NonCommercial-License, permitting copying and reproduction so long as the original work is given appropriate credit. Contents may not be used for commercial purposes, or adapted, remixed, transformed or built upon. (https://creativecommons.org/licenses/by-nc-nd/4.0/)

Thieme Medical and Scientific Publishers Pvt. Ltd., A-12, 2nd Floor, Sector 2, Noida-201301 UP, India 
their patients' needs and expectations. ${ }^{6}$ Unfortunately, even after having significant medical knowledge, the only way they could stop the transmission of infections during a pandemic is by discontinuing their regular practice. Hence, most of them remain isolated, spending their efficient hours without being productive which establishes a sense of hollowness and anxiety in their attitude. DHPs have already been notorious for stress related suicides. ${ }^{7,8}$ Therefore, there is a possibility that additional stressors during and after pandemics, wherein coping with depression is immensely challenging, may cultivate suicidal tendencies in many professionals.

As the pandemic of COVID-19 is expected to last longer, private practitioners and corporate organizations, which do not rely on any short-term or long-term government aids, are most likely to face harsh difficulties, both financially and in terms of achieving target patient footfall. Consequently, more DHPs could lose their jobs or suffer pay cuts. The fear and stress to deal with patients in the absence of appropriate vaccination would increase their anxiety leading to development of several psychological implications in them. Therefore, stress management is the need of the hour and governments of many nations have understood the importance of implementing the stress management strategies for the people. They have enumerated various techniques and provided online support for coping with stress caused by COVID-19. The WHO has published a stress management guide called "Doing what matters in Times of Stress: An Illustrated Guide" (print as well as audio files) that describes practical skills for people to cope up with stress for anyone and is backed by extensive field tested evidence. ${ }^{9}$ The Center of Disease Control and Prevention (CDC) has also suggested several ways to cope up with stress such as taking breaks from acquiring pandemics news, practicing meditation, eating healthy, exercising routinely, taking to people, and avoiding consumption of alcohol and smoking. They have also introduced hotline numbers to contact in case someone feels overwhelmed, depressed, anxious, or have suicidal feelings. ${ }^{10}$ Several other countries have followed these pathways and have started free mental health services to support their people. We additionally recommend that every organization should form a special team dedicated toward designing custom-made blueprints to follow during pandemics and should mandatorily include a clinical psychologist on their panel to help DHPs tackle anxiety and other mental health concerns. Most private corporate organizations tend to be patient centric to keep up their gains in business. In the light of pandemics or any other disaster-like situations, it is important to realize that they have to focus on DHPs by creating a judgement-free working environment, showing them gratitude, making them feel valued for their relentless efforts to adapt to the changing methods of treating patients and be empathetic so that they feel respected and understood about their concerns. This would slowly create positivity and build confidence in the entire team to work in unity. ${ }^{11}$

\section{Training and Education}

The COVID-19 pandemic has visibly exposed the potential gaps that exist in the public health emergency response in most countries, despite numerous state-of-the-art developments in the fields of science and technology. This is a wake-up call for us to be prepared for pandemics. DHPs undergo meticulous training in medical subjects, perform emergency procedures, prescribe medication, take oral swabs, and administer anesthesia during their education as well as throughout their career afterwards. These skills make them vital candidates for supporting national health services during pandemics. In excessive demand of physicians and other health-care providers, in hospital setups, local dentists and other DHPs could be recruited to provide their services to limit patient mortality and morbidity. ${ }^{12,13}$ Additionally, their participation would significantly influence medical surges $^{14}$ in times of pandemics.

Morlang had first proposed the potential of civilian DHPs in disaster response programs (DRPs) wherein they could develop skillsets required to augment the medical teams during disaster-like situations. He justified this by discussing how military DHPs are competent for performing under stressful warlike environments. ${ }^{15}$ Later, Guay described possible areas of participation by dentists, such as patient surveillance, referral to physicians, diagnosis on the basis of intraoral examinations, collection of oral and nasal swabs, monitoring of their infection/recovery status, conducting immunizations programs for DHPs and health-care providers, prescribing medications, ensuring maximum infection control in hospitals on the basis of their dental infection control expertise. Furthermore, a "Disaster Response Plan" had been proposed for the dental societies to consider while planning for disaster management strategies. ${ }^{13}$ The American Dental Association (ADA) also advises dentists to formulate plans for coping in disaster-like situations and provides consultation for the same. ${ }^{16}$ In 2005, an "Illinois Public Act" was proposed within Illinois (United States) that added roles of DHPs during a declared local, state, or national emergency, describing them as "dental emergency responder"17 (later amended to dental responder in 2015). ${ }^{18}$ After Illinois, California and Texas also adapted to this new defined roles of DHPs to combat disaster-like situations. ${ }^{18}$ In 2013, "Pandemic and All-Hazards Preparedness Reauthorization Act" legally authorized DHPs in United States to perform duties such as vaccination support in case of pandemics, acquiring biometrics, and forensic dentistry records in case of national emergency, disaster, and forensic needs. ${ }^{18}$

The above-described evidence highlights the need to implement newer roles for dentists all over the world. This can only be achieved by the development of newer policies by the governments in collaboration with respective dental councils to modify the dental teaching curriculum. Topics such as disaster management, conducting immunization sessions, and basic medical techniques should be included in public health dentistry. Moreover, conducting yearly certified disaster response drill as a part of continued education programs can be a good modification for keeping DHPs up-to-date with the necessary medical skills and practices necessary in case of pandemics. For instance, in an article, Motola et al have documented mass vaccination drill program in relation to influenza pandemic that was developed and conducted to 
train dental responders for pandemics. ${ }^{18,19} \mathrm{~A}$ similar approach can be used to integrate pandemic preparedness among dental students at an undergraduate level.

Additionally, in universities focus needs to be given on the investment and enhancements for online learning resources. The faculty and students need to be familiarized with guidelines to conduct online teaching and learning activities and trained to make these activities user friendly and engaging. Increasing the space on clouds, strengthening the information technology security for the remote access, and using new software enabling virtual applications can be very useful to ensure the delivery of curriculum up to profession's contextual needs and standards. An innovative, adaptable, needs focused curriculum can be considered to achieve a virtual learning environment integrated with authentic experiential learning.

\section{Financial Impact}

The economic impact of COVID-19 pandemic is expected to create a recession globally by the end of $2020 .{ }^{20}$ Worldwide, the dental community is going to be affected significantly as a result of an abrupt break in the dental practice for many DHPs and there are numerous reasons for the same. ${ }^{21}$ Setting up, running, and sustaining a dental practice itself is a capital-intensive task, which often puts the DHPs under huge financial constrain. Additionally, the average breakeven for the investment generally takes longer than most other professions. In the absence of support from the government or other authorities, many DHPs are facing a crisis situation. ${ }^{21}$ The rising questions about transformation of the clinics to refurbish patient waiting area may even lead to termination of practices with lesser available floor area especially in the developing countries. Until the vaccination is available, the cost of personal protective equipment (PPEs) will also add on to total monthly expenditure as the risk of asymptomatic patients and previously treated cases to spread infections could not be overlooked. Furthermore, the revenues of larger organizations and universities with multiple DHPs would be directly affected under the economic disruption that may delay several fixed expenses such as staff pays, rents, taxes, loan instalments, dental materials, and equipment suppliers. The finances of insurance companies are also stretched, which would propose added compensation cuts. ${ }^{21}$

It has been reported that periods of recession not only affect the DHPs financially at those times but also create a drop in the number of people seeking dental care postrecession. $^{22}$ These facts should encourage DHPs, particularly private practitioners to preplan and build strategies for coping in times of reduced patient inflow such as pandemics and disaster-like situations. In respect to the present COVID-19 pandemic, it is important that larger corporate organizations and universities prepare to get all their employees tested compulsorily before they get back to work. An ignorance in such a scenario could perpetuate spread of COVID-19 among employees that may lead to shutting down of the offices, producing huge financial setbacks. ${ }^{23}$ If a second wave of COVID-19 does arise, DHPs would be in a better position to safeguard their immediate financial needs and investments. Another important area of financial growth has been discussed by Ferneini who documented the importance of "telemedicine" as it is a safe platform to preform initial consultation with the patients remotely. This approach is not only manageable but also receives higher acceptance from the physicians, patients, government, and insurance sectors. Therefore, DHPs should also expand their scope of patient interactions to get past these uncertain times of the COVID-19 pandemic. ${ }^{21}$

\section{Dentistry-Associated Transmission of Infection}

The route of transmission of infections and development of disease outcomes is similar in both medical and dental setups. ${ }^{24-26}$ Over the years, the infection control in dentistry has significantly improved to prevent any transmission of bloodborne pathogens (BBPs). ${ }^{27}$ In 1985, the "Universal Precautions" (UP) ${ }^{28}$ were introduced to protect the health-care workers from BBPs, after which in 1987 "Body Substance Isolation"29,30 was added to UP to prevent the exposure from any "moist body substances" to DHPs. Later, in 1996, CDC introduced "standard precautions" 31 that added all body fluids to the principles of UP (for BBPs) to prevent cross-contamination between patients and health-care professionals. $^{25-31}$

During the previous pandemic of severe acute respiratory syndrome (SARS) in 2003, large outbreaks were caused among health-care workers because of aerosols produced from medical procedures. ${ }^{32-34}$ The saliva was not identified to be contaminated as opposed to secretions from the respiratory tract at that time. ${ }^{34}$ However, the recent COVID-19 virus could be transmitted through saliva as it has been identified in the saliva of infected patients consistently. ${ }^{35}$ Azzi et $\mathrm{al}^{36}$ have highlighted the potential of saliva as a diagnostic tool for COVID-19 infections and have emphasized that patients viral load in saliva must be evaluated before discharge from the hospital. ${ }^{36}$ Furthermore, $\mathrm{Xu}$ et $\mathrm{al}^{37}$ have reported the spread of COVID-19 virus from asymptomatic patients that may have originated from their infected saliva, as a result, salivary glands could be a reservoir of COVID-19 virus in asymptomatic patients. ${ }^{37}$

The aforementioned evidence shows how critical it is to understand different pathways of spread in times of pandemics. Commonly, the dental clinics and hospitals are compartmentalized into separate working zones, thereby isolating the disinfected chair side settings from front desk and patient waiting area. This facilitates in maintaining effective infection control strategies and limiting the chances of cross-contamination. Routinely, all patients are screened for past and existing medical history and they sign an informed consent document before entering into the treatment area. This also gives a clear information about the patient's health status to the dentist. However, in times of pandemics, it may be expected that not all individuals are aware of their disease status as there are circumstances when healthy carriers become infectious and develop symptoms just before 
1 day, in such cases there is a high chance of unawareness of their infection history and source. ${ }^{38}$ Moreover, the incubation period also varies in different pandemic infections, for instance, during avian influenza $\mathrm{A} / \mathrm{H} 5 \mathrm{~N} 1$ pandemic the reported incubation period has been 2 to 4 days, up to 8 days, ${ }^{38,39}$ for SARS pandemic 2 to 7 days, up to 10 days, ${ }^{34}$ and for COVID-19 pandemic 2 to 14 days with possible outliers up to 27 days. ${ }^{40,41}$ Hence, it is extremely important to identify a symptomatic patient who poses the highest risk for transmission of infection.

Oral examination as well as treatment may induce coughing and lead to production of aerosols. The aerosols remain suspended in air for several hours and may get settled on the surfaces such as cabinet tops specially if not disinfected immediately after the completion of dental treatment. Evidence from a systematic review suggested that aerosol producing procedures (APP) were a risk factor for transmission of SARS to health-care professionals. ${ }^{42}$ Recently, in an experimental study, van Doremalen et a ${ }^{43}$ reported that the COVID-19 virus can remain adhered for up to 3 hours in the aerosols. Hence, DHPs along with the next patients who enter an aerosol contaminated treatment area would have a high probability of getting COVID-19. In case of COVID-19 or other acute infectious respiratory infections, the aerosols can be reduced by the adopting the procedures such as by scheduling one patient at a time in the dental office; isolating all sterile instruments and dental supplies in closed storage areas; minimizing the contents in the operatory including art works, wall hangings, and plants; advising the patient to do preprocedural mouth rinse with $1 \%$ povidone iodine or 1 to $1.5 \%$ hydrogen peroxide for 60 seconds before intraoral examination; avoiding use of rotary low/high speed handpieces, ultrasonic scalers, and three-way air/water syringe; using hand instruments and perform a minimally invasive dentistry; and performing a four-hand dentistry approach with use of rubber dam and continuous high evacuation suction. ${ }^{44,45}$ If APP are done, they should be done in an operatory that is completely isolated from adjacent rooms with floor to ceiling walls and doors. If temporary walls and door are being constructed, they should be able to contain the aerosols and must be of a good quality material that can repeatedly cleaned and disinfected. ${ }^{45,46}$

\section{Discussion}

Patients of all age groups report numerous emergencies in a dental office. Most of these emergencies are associated with pain, intra/extra oral swelling, and acute/chronic/acute exacerbation of chronic infections. However, in times of pandemics "defining an emergency" is critical to limit the number of patients seeking dental care. This step is necessary to maintain the highest levels of infection control in the dental office. During the recent COVID-19 pandemic, the Royal College of Dental Surgeons of Ontario ${ }^{44}$ as well as $\mathrm{ADA}^{46}$ has defined dental emergency, urgent care, and nonessential care for DHPs to follow. The $\mathrm{CDC}^{45}$ has recommended that all elective, nonessential procedures should be delayed and only emergency and urgent dental treatments should be prioritized to preserve PPEs and protect the others DHPs in the dental office. This is where teledentistry would ease the process of triage and facilitate a strategic management of patients. In teledentistry, a licensed dentist uses live or recorded dental health information such as videos, images, and radiographs and communicates online with the patients seeking dental care while they are not visiting the dental office in person ${ }^{47}$ The ADA has suggested that its integration into the routine dental practice could successfully support dentists for a staged return to normal practice.

The infrastructure of the dental office has to be prepared efficiently before it becomes available for the treatment of routine and COVID-19 patients. DHPs are advised to put important visual alert signs, posters, or video demonstrating hand hygiene, respiratory, cough etiquettes, and social distancing while refurbishing the entrance and patient waiting area. ${ }^{45}$ Patient shall be provided a 60 to $95 \%$ alcohol-based hand rub, surgical mask, and tissue paper. Motion sensing or touchless trash bins shall be used. There shall be at least a 6-feet or 2-meter distance between dental chairs with no items such as toys, books, and newspapers. The number of people waiting in the waiting area shall be limited and if needed then they shall be requested to wait outside or in their personal vehicle and be informed to enter the clinic only on their turn. Physical barrier window either of plastic or glass, easy-to-clean floor-to-ceiling barriers separating entrance, waiting area, lobby area, sterilization room, and operatory shall be used. ${ }^{45}$

It is important that only one patient is scheduled at a time to ensure maximum infection control, thereby limiting the chance of cross-contamination between patients. The dental-unit waterlines, autoclaves, radiography apparatus, air compressor, suction lines, and other essential dental equipment must be prechecked and maintained to avoid prolongation of treatment time. In case, the dental office had been closed for a long time, guidelines have been specified by CDC for reopening. 48

A flowchart should be prepared to understand the protocol to manage the patient systematically from teleconsultation to in-clinic treatment both in presence and absence of COVID-19. Patients history and consent form should be filled and send online to the dentist before triaging. First patient's demographic history, chief complaint, medical history, past dental history, family history, recent travel history, medication and allergy history, COVID-19 history (active/recovered/ tested negative), symptoms consistent with COVID-19 such as cough and breathing difficulty should be assessed. Then teledentistry to consult, triage, and schedule patients by licensed dentists should be used. Patients with emergency and urgent care needs may further require in-clinic examination. Patients with nonessential needs can be consulted through teledentistry and scheduled for an in-clinic visit if required. Patients should be advised to limit the number of accompanying family members if they are scheduled for an appointment. However, in case of appearance, they should be requested to undergo screening for COVID-19 symptoms and fever. They should also be asked to wear a mask and follow social distancing protocols. 
However, if a suspected and unconfirmed COVID-19 patient presents at the clinic without prior teleconsultation, the dentist should defer treatment, advise the patient to wear a mask, go home, and call their primary care provider. This could be done only when the patient is not acutely sick. If the patient is acutely sick showing symptoms of difficulty in breathing, etc., then the patient should be referred to a nearby hospital or the emergency response number should be called. ${ }^{44}$ In case, an emergency dental treatment is necessary, dentists must follow CDC's "Interim Infection Prevention and Control Recommendations for Patients with Suspected/ COVID-19 in Healthcare Settings and use of PPE." ${ }^{19}$ The PPE must include N95 respirator/equivalent high level respirator with good fitting and seal checked, gloves, face shield, eye protection, and protective gown. ${ }^{50}$ It is important to understand that all APP should ideally be done in negative pressure isolation rooms. Additionally, the patients could be scheduled last, in the absence of other patients. ${ }^{44,45}$ After a home self-isolation of 14 days, the patients could be treated following standard precautions. It is mandatory to for all DHPs that if a surgical mask $^{51,52}$ and full-face shield are not available, APPs must not be performed. ${ }^{45,52}$

The disinfection of operatory and other sections of the dental office is very critical. The CDC recommends the infection control protocol, before and after patient leaves the operatory, has to be followed as per "Guidelines for Infection Control in Dental Health-Care Settings-2003." ${ }^{53}$ To clean and disinfect the operatory after an unconfirmed COVID-19 patient leaves the operatory, a gap of fifteen minutes should be given. However, after a confirmed COVID-19 patient leaves, "adequate time" ${ }^{54}$ must be given for the necessary air changes to happen. This would eliminate infectious pathogens from the air. The maintenance of clean air is extremely important to avoid airborne transmission of infection. The air-cleaning equipment that provide ventilation through movement of air from a clean dentist work area to contaminated patient treatment area direction must be installed and accurately maintained. The washroom exhaust fans must continuously run during the working hours. The DHPs should consult a "heating, ventilation and air conditioning" expert to increase the proportion of outdoor air supply and airflow direction mechanics of the clinic to achieve efficient ventilation. A portable high-efficiency particulate air (HEPA) air-filtration unit could be used especially when the patient is undergoing APPs and also after the treatment is finished. It would not only decrease aerosol particles including droplets but also decrease the turnover time. ${ }^{45,46}$ Although several alternative disinfection methods such as high-intensity UV radiation, ultrasonic waves, and LED blue-light have been suggested, their efficacy is still not known but can be used as adjunctive to HEPA air-filtration unit. ${ }^{46}$

\section{Conclusion}

COVID-19 pandemic has made a strong unavoidable impression on dentistry and posed many challenging situations to achieve an efficient patient and DHP's protection. This review has highlighted various impacts of this pandemic situations in dentistry and emphasized on certain evidence-based strategies to overcome these challenges. Teledentistry is expected to play a very strong role henceforth in practicing safe and efficient dentistry. Lastly, it is important that the dental institutions must focus on developing pandemic-management skills in the future DHPs so that they are ready to deal with adverse situations themselves, while also supporting their fellow medical professionals.

\section{Conflict of Interest}

None declared.

\section{References}

1 Moynihan P. The British Nutrition Foundation Oral Task Force report-issues relevant to dental health professionals. Br Dent J 2000;188(6):308-312

2 Meng L, Hua F, Bian Z. Coronavirus disease 2019 (COVID-19): emerging and future challenges for dental and oral medicine. J Dent Res 2020;99(5):481-487

3 Rothe C, Schunk M, Sothmann P, et al. Transmission of 2019-nCoV infection from an asymptomatic contact in Germany. N Engl J Med 2020;382(10):970-971

4 Cucinotta D, Vanelli M. WHO declares COVID-19 a pandemic. Acta bio-medica. Acta Biomed 2020;91(1):157-160

5 Coulthard P. Dentistry and coronavirus (COVID-19) - moral decision-making. Br Dent J 2020;228(7):503-505

6 American Dental Association. Ada calls upon dentists to postpone elective procedures. Available at: https:// www.ada.org/en/pressroom/news-releases/2020- archives/march/ada-calls-upon-dentists-to-postponeelective-procedures. Accessed Aug 29, 2020

7 Alexander RE. Stress-related suicide by dentists and other health care workers. Fact or folklore? J Am Dent Assoc 2001;132(6):786-794

8 Sancho FM, Ruiz CN. Risk of suicide amongst dentists: myth or reality. ? Int Dent J 2010;60(6):411-418

9 World Health Organization. Doing what matters in times of stress: an illustrated guide. 2020). Available at: https://apps.who.int/iris/ bitstream/handle/10665/331901/9789240003910-eng.pdf.

10 Centers for Disease Control and Prevention. Coping with stress. Available at: https://www.cdc.gov/coronavirus/2019-ncov/daily-life-coping/managing-stress-anxiety.html. Accessed Aug 29, 2020

11 Singer T, Klimecki OM. Empathy and compassion. Curr Biol 2014;24(18):R875-R878

12 Guay AH. Dentistry's response to bioterrorism: a report of a consensus workshop.J Am Dent Assoc 2002;133(9):1181-1187

13 Guay AH. The role dentists can play in mass casualty and disaster events. Dent Clin North Am 2007;51(4):767-778, v

14 Watson SK, Rudge JW, Coker R. Health systems' “surge capacity": state of the art and priorities for future research. Milbank Q 2013;91(1):78-122

15 Morlang WM. Dentistry's vital role in disaster preparedness. J Calif Dent Assoc 1996;24(5):63-66

16 Chmar JE, Ranney RR, Guay AH, Haden NK, Valachovic RW. Incorporating bioterrorism training into dental education: report of ADA-ADEA terrorism and mass casualty curriculum development workshop. J Dent Educ 2004;68(11):1196-1199

17 Colvard MD, Lampiris LN, Cordell GA, et al. The dental emergency responder: expanding the scope of dental practice. J Am Dent Assoc 2006;137(4):468-473

18 Colvard MD, Vesper BJ, Kaste LM, et al. The evolving role of dental responders on interprofessional emergency response teams. Dent Clin North Am 2016;60(4):907-920 
19 Motola I, Burns WA, Brotons AA, et al. Just-in-time learning is effective in helping first responders manage weapons of mass destruction events. J Trauma Acute Care Surg 2015;79(4, Suppl 2) :S152-S156

20 McKinsey \& Company. COVID-19: Implications for business. Available at: https://www.mckinsey.com/business-functions/ risk/our-insights/covid-19-implications-for-business. Accessed Aug 29, 2020

21 Ferneini EM. The financial impact of COVID-19 on our practice. J Oral Maxillofac Surg 2020;78(7):1047-1048

22 Guay AH, Blatz A. The effect of the Great Recession on the demand for general oral health care and orthodontic care. J Am Dent Assoc 2019;150(4):287-293

23 Baldwin R, di Mauro BW. Mitigating the COVID economic crisis: Act fast and do whatever it takes. VoxEU. org eBook 2020. Available at: https://voxeu.org/content/mitigating-covid-economic-crisis-act-fast-and-do-whatever-it-takes.

24 Favero MS, Bond WW, Chemical disinfection of medical and surgical materials. In: Block SS, ed. Disinfection, Sterilization, and Preservation. Philadelphia: Lea \& Febiger; 1991:617-641

25 Molinari JA. Infection control: its evolution to the current standard precautions. J Am Dent Assoc 2003;134(5):569-574, quiz 631-632

26 Centers for Disease Control (CDC). Update-transmission of HIV infection during an invasive dental procedure-Florida. MMWR Morb Mortal Wkly Rep 1991;40(2):21-33

27 Centers for Disease Control and Prevention. Recommended infection-control practices for dentistry, 1993. MMWR Recomm Rep 1993;42(RR-8) :1-12

28 Centers for Disease Control (CDC). Recommended infection-control practices for dentistry. MMWR Morb Mortal Wkly Rep 1986;35(15):237-242

29 Lynch P, Jackson MM, Cummings MJ, Stamm WE. Rethinking the role of isolation practices in the prevention of nosocomial infections. Ann Intern Med 1987;107(2):243-246

30 Lynch P, Cummings MJ, Roberts PL, Herriott MJ, Yates B, Stamm WE. Implementing and evaluating a system of generic infection precautions: body substance isolation. Am J Infect Control 1990;18(1):1-12

31 Garner JS; The Hospital Infection Control Practices Advisory Committee. Guideline for isolation precautions in hospitals. Infect Control Hosp Epidemiol 1996;17(1):53-80

32 Centers for Disease Control and Prevention. Supplement I: Infection control in healthcare, home, and community settings. Public health guidance for community-level preparedness and response to severe acute respiratory syndrome (SARS) Version. 2004;2. Available at: https://www.cdc.gov/sars/guidance/i-infection/healthcare.pdf.

33 Seto WH, Tsang D, Yung RW, et al; Advisors of Expert SARS group of Hospital Authority. Effectiveness of precautions against droplets and contact in prevention of nosocomial transmission of severe acute respiratory syndrome (SARS) Lancet 2003;361(9368):1519-1520

34 Samaranayake LP, Peiris M. Severe acute respiratory syndrome and dentistry: a retrospective view. J Am Dent Assoc 2004;135(9):1292-1302

35 To KK, Tsang OT, Yip CC, et al. Consistent detection of 2019 novel coronavirus in saliva. Clin Infect Dis 2020;71(15):841-843

36 Azzi L, Carcano G, Gianfagna F, et al. Saliva is a reliable tool to detect SARS-CoV-2. J Infect 2020;81(1):e45-e50

37 Xu J, Li Y, Gan F, Du Y, Yao Y. Salivary glands: potential reservoirs for COVID-19 asymptomatic infection. J Dent Res 2020; 99(8):989-989

38 Collignon PJ, Carnie JA. Infection control and pandemic influenza. Med J Aust 2006;185(S10) :S54-S57
39 Beigel JH, Farrar J, Han AM, et al; Writing Committee of the World Health Organization (WHO) Consultation on Human Influenza A/H5. Avian influenza A (H5N1) infection in humans. N Engl J Med 2005;353(13):1374-1385

40 Centers for Disease Control and Prevention. Symptoms of novel coronavirus (2019-nCoV). Available at: https://www.cdc.gov/ coronavirus/2019-ncov/symptoms-testing/symptoms.html Accessed Aug 29, 2020

41 Shen S, Woo R. Coronavirus incubation could be as long as 27 days, Chinese provincial government says. UK: Reuters 20202. Available at: https://www.reuters.com/article/us-china-health-incubation/ coronavirus-incubation-could-be-as-long-as-27-days-chineseprovincial-government-says-idUSKCN20G06W.

42 Tran K, Cimon K, Severn M, Pessoa-Silva CL, Conly J. Aerosol generating procedures and risk of transmission of acute respiratory infections to healthcare workers: a systematic review. PLoS One 2012;7(4):e35797

43 van Doremalen N, Bushmaker T, Morris DH, et al. Aerosol and surface stability of SARS-CoV-2 as compared with SARS-CoV-1. N Engl J Med 2020;382(16):1564-1567

44 Royal College of Dental Surgeon of Ontario. RCDSO_definitions_dental_care.pdf. Available at: https://cdn.agilitycms. com/rcdso/pdf/RCDSO_definitions_dental_care.pdf. Accessed Aug 29, 2020

45 Centers for Disease Control and Prevention. Guidance for dental settings. Available at: https://www.cdc.gov/coronavirus/2019-ncov/hcp/dental-settings.html\#Management. Accessed Aug 29, 2020

46 American Dental Association. ADA.org: What constitutes a dental emergency? Available at: http://success.ada.org/ / media/CPS/Files/Open\%20Files/ADA_COVID19_Dental_ Emergency_DDS. Accessed Aug 29, 2020

47 Royal College of Dental Surgeon of Ontario. COVID-19: Guidance for the use of teledentistry. Available at: https:// www.rcdso.org/en-ca/rcdso-members/2019-novel-coronavirus/covid-19-emergency-screening-of-dental-patients-using-teledentistry. Accessed Aug 29, 2020

48 Guidance for Reopening Buildings After Prolonged Shutdown or Reduced Operation. https://www.cdc.gov/coronavirus/2019-ncov/ php/building-water-system.html

49 Centers for Disease Control and Prevention. Interim infection prevention and control recommendations for patients with suspected or confirmed coronavirus disease 2019 (COVID-19) in healthcare settings. Available at: https://www.cdc.gov/ coronavirus/2019-ncov/hcp/infection-control-recommendations.html. Accessed Aug 29, 2020

50 Food US, Drug N. 95 respirators, surgical masks, and face masks. Available at: https://www.fda.gov/medical-devices/ personal-protective-equipment-infection-control/n95-respirators-and-surgical-masks-face-masks. Accessed Aug 29, 2020

51 American Dental Association. ADA interim mask and face shield guidelines. Available at: https://success.ada.org/ /media/CPS/ Files/COVID/ADA_Interim_Mask_and_Face_Shield_Guidelines. pdf. Accessed Aug 29, 2020

52 Centers for Disease Control and Prevention. Guidelines for infection control in dental health-care settings - 2003. Available at: https://www.cdc.gov/mmwr/PDF/rr/rr5217.pdf. Accessed Aug 29, 2020

53 Centers for Disease Control and Prevention. Appendix B. Air. Available at: https://www.cdc.gov/infectioncontrol/guidelines/ environmental/appendix/air.html\#tableb1. Accessed Aug 29, 2020

54 Centers for Disease Control and Prevention. Using personal protective equipment (PPE). Available at: https://www.cdc.gov/coronavirus/2019-ncov/hcp/using-ppe.html. Accessed Aug 29, 2020 